\title{
Promoting Refugee Law as a Means of Challenging the Status Quo at University Level Education In Europe: The Role of the Refugee Law Clinic
}

Stephan Anagnost ${ }^{1}$

The purpose of this paper is to provide a look into the state of the art of clinical legal education at select European universities, using refugee law clinics as a model.

In addition, this article will look into the work to date at refugee law clinics in the Central European and Baltic States (CEBS) and Western Europe and their prospects for the future.

Finally, it is the purpose of this article to explore a number of the trans-Atlantic initiatives between legal-aid and legal clinic programs.

1 The author, Director of Legal Aid - Legal Clinics (developing human rights, migration and asylum related training tools, legal aid and protection solutions: www.la-lc.org), is a lecturer on human rights and protection issues. He currently serves as the Human Rights Co-ordinator of the Organisation for Security and Co-operation in Europe Mission in Kosovo
(OSCEMIK) and has served as the United Nations High Commissioner for Refugees Project manager of the Phare Horizontal Program towards Asylum System development (PHA). The opinions in this article do not necessarily reflect those of the OSCE or the United Nations. 


\section{THE CONTEXT: LEGAL AID FOR ASYLUM SEEKERS AND REFUGEES IN EUROPE TODAY}

Legal aid for asylum seekers and refugees remains a major challenge in the CEBS and Western Europe. Affordable legal aid that is both accessible and of high quality is being provided by a select few inter-, non- and governmental agencies, but it is often not enough. ${ }^{2}$ Resources for the protection of refugees such as capacity, funds and time are scarce commodities throughout the region and they are often expended without being replenished.

Accession to the EU, ${ }^{3}$ in particular the implementation of the EU's 1995 Resolution on Minimum Guarantees for Asylum Procedures, ${ }^{4}$ has brought the question of legal aid for asylum seekers and refugees to the forefront of the discussion. ${ }^{5}$ The development of high quality, low cost legal aid structures remains a low priority.

\subsection{Developing protection systems}

The majority of CEBS are currently "transit countries"; states that are normally traveled through by asylum seekers towards their intended country of asylum. Asylum applications remain below that of the average for European Union Member States, for example, in some CEBS over $40 \%$ of all asylum applicants leave the asylum procedure. In others there are no recognized refugees. These are trends that are expected to change as the CEBS move closer towards membership of the European Union.

States are obligated to provide forms of legal aid to asylum seekers and refugees but in most States the form of legal aid is not specified nor is the level of qualification of the aid provider. In many cases funding for legal aid is not guaranteed by the State. These issues will be discussed in more detail below.

\subsection{Protection providers}

In the CEBS therefore, the responsibility for providing this legal aid ultimately falls on the shoulders of the primary care giver; the asylum and refugee attorney. It is the asylum and refugee attorney who spends the extra hours researching each case and reviewing the country of origin information and the rationale behind a negative decision. This is a time-consuming process undertaken by someone who normally has an additional caseload. Furthermore, the typical asylum and refugee attorney in the CEBS faces sometimes severe earnings discrepancies compared with attorneys in other fields. The current economic situation in the CEBS dictates a number of seemingly contradictory priorities.

Funding such a necessary process has been taken on in part by a number of CEBS governments, but again, economic realities have placed limits on the extent to which a State can effectively provide such legal aid. Non governmental organisations (NGOs) have filled this gap, taking on elements of legal aid and social support for asylum seekers and refugees.

2 Funding for legal aid in the CEBS comes mainly from UNHCR.

3 Which includes the implementation of the elements of the EU acquis on asylum.

4 Paragraph 13.2 of the EU MG stipulates the right of an asylum seeker to legal aid during the procedure.
5 The 1999-2000 Phare Horizontal Program Asylum (PHA), one of the many accession tools, has as a focus the improvement of legal aid structures and capacities in the CEBS. During the course of the PHA the legal aid structures were analyzed and it became clear that many State were unaware of their obligations to provide legal aid. 
NGOs, with UNHCR support, shoulder the bulk of the protection work. A number of networks exist to provide additional support ${ }^{6}$ but funding remains the greatest barrier to the continued provision of quality legal aid.?

\subsection{Scarce protection resources and limited capacities}

The largest contributor of "protection resources" towards legal aid is UNHCR, whose offices in the CEBS provide the majority of the direct or indirect financial and/or other support. ${ }^{8} \mathrm{UNHCR}$, however, will not maintain this level of support indefinitely, so other protection sources need to be found. ${ }^{9}$

The EU and EU Member States have only begun to recognize the need for increased investment in legal aid structures for the CEBS ${ }^{10}$. Current resource providers are shifting their focus and at the present moment the budgets of the CEBS do not provide substantial support for legal aid. ${ }^{11}$ An interim solution will need to be found until additional resources can be found and States' budgets effectively reflect their obligation to provide legal aid.

Different measures have been undertaken by a number of actors in order to increase the capacity of the CEBS regarding the provision of legal aid for asylum seekers and refugees. One such approach, following the model offered by a number of North American universities, utilizes a bountiful resource that largely remains overlooked and untapped in the CEBS: university law students.

\section{THE ROLE OF REFUGEE LAW CLINICS}

Refugee law clinics (or simply "clinics" as they are known) represent a cost effective way to provide high quality legal aid to asylum seekers and refugees. ${ }^{12}$ They are based on the model offered in many North American universities where law students study the theoretical elements of domestic and international refugee law and apply this theory in practice through protection work as a legal aid assistants/ex-terns under the supervision of an attorney or lawyer working with "live clients": asylum seekers and refugees. This allows students to provide direct legal aid to asylum seekers and refugees or support services to NGOs, attorneys and lawyers who provide legal aid and increases the capacity and efficiency of domestic protection resources. ${ }^{13}$

6 The Asylum Rights Support Initiative (ARSI) is a legal aid network including Austrian, Bulgarian, Czech, Hungarian, Lithuanian, Romanian, Slovak and Slovene NGOs. The European Council for Refugees and Exiles (ECRE), and umbrella organization made up of EU NGOs, began a CEBS forum known as CEFRAN which has been dormant since 1998. ECRE also provides occasional training through its legal network (ELENA).

7 State support is also not forthcoming, see below.

8 UNHCR maintains offices in each CEBS.

9 Since 1997 UNHCR has encouraged legal aid providers to begin to diversify their funding base, sending joint proposals to the EU Odysseus, EIDHR and ERF programs for consideration.

10 In contrast the EU and EU Member States combined have invested over 20 million Euro towards the development of border regimes.
11 Individual State legal aid providers and ARSI partners have submitted applications for funding to the Odysseus and EIDHR programs respectively.

12 For a more comprehensive look at clinical legal education see Aubrey McCutcheon, "University Legal Aid Clinics: A Growing International Presence with Manifold Benefits," Journal of Legal Education 58 (1998).

13 In addition to providing free legal assistance, many clinics monitor conditions at refugee centers and detention centers, report on the living conditions of Roma communities, and provide a year-long training in human rights to secondary school students. Others have been active in organizing conferences on legal education for universities in the CEBS. 


\subsection{Clinics as protection and education}

Working side-by-side with a practicing asylum lawyers also exposes the student to the day-to-day difficulties which the average attorney faces, consequently sharing with the attorney the satisfaction one receives by providing basic and more sophisticated humanitarian protection. The support provided to the asylum seeker or refugee by the student also shows a certain degree of respect and dignity towards a human being whose life has been threatened, who has been forced to flee his or her country and who is faced with the daunting task of accepting these experiences and starting over. Such support is priceless, such an opportunity unique.

After an intensive and comprehensive theoretical course on national and international aspects of refugee and asylum law, students, supervised by a qualified and recognized attorney, are introduced to an asylum seeker, "client", and the specifics of his or her case. Students may be expected to interview the client, research the facts of the case including the relevant country of origin information and the preliminary decision of the first instance, find an interpreter, prepare the briefing notes and case file, or perform any number of other tasks which go into the preparation of an asylum application or appeal. In many clinics the student assists the asylum and refugee attorney either directly or indirectly as he or she prepares the case.

In addition to encouraging good humanitarian attitudes,${ }^{14}$ enhancing the student's protection interest and strengthening necessary lawyering skills, this combination of theory and practice gives the participating student a complete overview of the national protection scheme and domestic asylum system ${ }^{15}$ (legislation, actors, practice) and further provides insight into the complex and demanding field of refugee law.

\subsection{Some benchmarks}

Clinics need to be fully associated with a university, its law faculty and board of study and should strive to provide high quality, low cost legal aid to asylum seekers and refugees. In addition a clinic should be run by a manager, supervising lawyer and university professor who take ownership for the clinic. There should be active student support and enrollment. The clinic should be a fixed element in the law school curricula, it should have reasonable access to a client base, identified sources of funding and receive active support from NGOs, law firms and other protection organizations.

\subsection{Comparisons...}

Clinics in North America supplement or complement domestic protection and legal aid structures (the oldest is over twenty years old). They are supported by active and well endowed university structures, established NGOs, well trained professors, lawyers with decades of refugee law experience and active, dedicated students. They are also properly organized and managed in a similar way to a law office. It is no wonder that UNHCR conserves its protection resources in North America and plays more the role of monitor in these States. The quality of service provided has not been questioned to date.

14 For example during the humanitarian evacuation of Kosovar refugees to Poland, the Jagiellonian University human rights clinic assisted by briefing Kosovars wishing to voluntarily return concerning the situation in Kosovo, as well as the legal ramifications should they choose to remain in Poland.
15 In fact, during 1998, a clinic in Poland was responsible for successfully supporting two precedence-setting cases related to asylum seekers. 
In the CEBS and CIS clinics are new actors on the scene (Jagiellonian University human rights clinic in Cracow at three years is the oldest). Since 1997 Cracow has been joined by Warsaw as the only other refugee law clinic in Poland, Budapest (with two ELTE \& KLTE), Györ and Debrecen have developed in Hungary, Prague (Charles University) in the Czech Republic, Latvia University in Riga, Concordia International University in Tallinn Estonia, Moldova State University in Chisinau and number of other developing legal aid and refugee law programs in the region, too young to be yet determined as clinics.

These clinics lack the well endowed university structures, established NGOs and professors and lawyers with decades of refugee law experience that their North American counterparts have. ${ }^{16}$ As mentioned above standards for legal aid do not exist. In general clinics are not poorly managed but they simply lack skilled, well trained managers. They do have committed and dedicated professors, students and lawyers.

Clinics have been praised by national decision takers and UNHCR offices for their attention to detail and high quality. ${ }^{17}$ One remaining concern is that without basic standards unguided clinics run the risk of taking cases which fall out of the scope of the clinic, thus bringing non-refugees into the asylum procedure.

\section{4 ... and cooperation}

An interesting fusion of North American and CEBS legal aid providers has developed. ${ }^{18}$ Concerned with the state of affairs regarding legal aid in the CEBS, legal aid and university representatives from both regions met in two refugee law clinic working seminars. ${ }^{20}$ The seminars have focused on developing a set of legal aid provision and management standards as well as to draft a model refugee law course curriculum and resource package. ${ }^{21}$ The result of these developments will be introduced in the second half of $2000^{22}$ and further clinic development is planned for early 2001 in the EU and CIS.

\subsection{Maintaining the protection interest}

UNHCR's protection interest is its core and lifeblood. Regarding legal aid for asylum seekers it would be difficult to find a national context worldwide where UNHCR does not play some role, be it as an element of the national status determination procedure, training of officials and/or legal aid providers, or as a monitor of the quality of aid and decisions taken.

Quality is a concern, cost is an issue. An overcrowded national legal aid structure reduces quality and raises costs, therefore streamlining is important. Low quality legal aid will lead to poor decision taking, asylum seekers may be sent back to situations of persecution, remain in detention

16 For an overview of the refugee law clinic experience in North America see Richard Wilson, "Clinical Legal Education for Human Rights Advocates," Human Rights Education in the Twenty-First Century (1997).

17 The high quality of the appeals drafted by students in Hungary and Poland has done much to dispel the initial skepticism exhibited by the Ministry of Interior toward the students.

18 These meetings have been sponsored by UNHCR and the Constitutional and Legal Policy Institute (COLPI), a member of the Soros network.
19 Western European actors were also invited but did not attend.

20 Both seminars took place in Cracow, hosted in part by the Jagiellonian clinic, COLPI and UNHCR.

21 The Hungarian Helsinki Committee, the Czech NGO OPU, the Lawyers Committee for Human Rights, Catholic Charities and UNHCR are working on the set of standards. 
or otherwise be placed in situations where the dignity of the individual is compromised. Unguided legal aid, from any provider, is a grave mistake. Therefore, as a protection solution, clinics fall within the direct protection interest of UNHCR to guarantee high quality, low cost legal aid.

The future development of the protection interest of States and other actors will depend on the extent to which they have been effectively exposed to refugee law and asylum culture. Poorly structured this will have negative ramifications in the decision taking process, the provision of legal aid and integration of refugees.

As a means of advancing refugee law and asylum culture, clinics place refugee law courses in the yearly course selection and curricula of the host university. This provides an opportunity to reach a large audience with minimal investment. Furthermore, in keeping with UNHCR's advancement of refugee law and asylum culture policy, clinics fall within the scope of UNHCR's Executive Committee Conclusions number 51 “...underlining the need to develop practical applications of refugee law and principles and the importance of training courses in refugee law and protection...". ${ }^{23}$

\subsection{Complimentarity of the clinics}

As a legal aid solution the clinics are an inexpensive complement to existing legal aid structures. Clinics provide their service for free or for a minimal fee and have only the fixed costs that are common in most NGOs and law offices. As a long term legal aid solution, clinics train and integrate the next generation of asylum system practitioners ${ }^{24}$ at a fraction of the price were this training to take place at the workforce level. ${ }^{25}$

The activities of the refugee law clinics have shown that with relatively little money, a credible legal assistance program can be developed, which can serve to provide a boost to badly needed legal assistance in the short-term, and at the same time, ensure that there is a systematic development of skills and competencies of potential actors in their respective asylum systems on a long term basis.

\section{POINTS TO CONSIDER}

Clinical legal education, while not completely foreign in Europe, is clearly a new frontier. In some universities the concept of the clinic has been accepted, in others there is an active effort to stall its progress. There are a number of reasons for the current state of affairs and this paper will address them below.

\subsection{Resistance to clinics}

That some solid refugee law clinic models exist points to a certain degree of focussed success stories. The concept has on the whole been resisted by universities, professors and the legal aid community that clinics seek to support. This resistance developed for a number of reasons:

22 In the form of a Regional Seminar hosted by the Hungarian Helsinki Committee, COLPI and UNHCR.

231988 Executive Committee 39th Session No. 51 "Promotion and Dissemination of Refugee Law"

24 The students who took part in the clinics have gone on to intern inter alia at the Council of Europe's Directorate of Legal Affairs Ad Hoc Committee on Asylum,
Refugees, and Stateless Persons; Foreign Ministries; UNDP; and UNHCR.

25 At the current rate every dollar invested in training one decision taker on the basics of the refugee definition would be equal to training three clinic students in the same topic. 
- Timing: Clinics arrived on the shores of Europe as a North American product at a moment when Europe was interested in creating a sense of cultural as well as political independence. Concepts that appear to have North American roots are often rejected out of hand.

- Poorly packaged, poorly sold: Clinics in general and refugee law clinics in particular did not receive the proper cultural filter at first. Clinical legal education lacked a coherent guiding agency that could support developing programs and help to dispel myths.

- Bad development plans: In two cases, one at Charles University in Prague, the other in Bucharest in Romania, a rather sophomoric strategy was initiated by a proponent of the clinic model that resulted in a complete rejection of clinical legal education by the deans of both schools. ${ }^{26}$

- Competition: Bar Associations have seen clinics as potential rival rather than a complement.

- Tradition: Many law schools pride themselves on their "straight lecture" style of teaching.

- Existence of practice opportunities: A number of universities already have externship opportunities.

- Limited incentives: Most law schools are State funded.

- 'Ivory tower' syndrome: Professors see their role and the role of the university as one of provider of theoretical knowledge. They therefore ignore the growing client base for human rights and poverty clinics. ${ }^{27}$

The lack of well endowed universities in Europe leads to an additional argument against certain clinics and clinical models. With refugee law clinics there are a number of organizations and the UNHCR that might step in to support the development of existing clinics. Other human rights and poverty oriented clinics do not have such "engines" or motors behind them. This is a crucial argument and one that is most convincing.

\subsection{Arguments in favor}

There are a number of points that make clinical education development difficult. These are well countered with a number of arguments in favor of clinical development:

- Perfect timing: European universities are coming under pressure to become more self sufficient. ${ }^{28}$ While this current development will probably not lead to tuition driven universities, it does mean that European universities will undergo major changes in the years to come. Law programs will need to be streamlined and made more attractive to potential students. A clinical program would certainly add weight to any university program.

- $\quad$ Failure of existing extern-ships: Both Austrian and German law schools provide a practical period for all junior lawyers wanting to join the bar. As these opportunities arise only after the main course of study has been completed, externships hosts (law firms, judges, ministries, etc.) are forced to retrain the junior lawyers. This costs time and money.

26 In the case of Charles University, the Public Interest Law Initiative (PILI) recommended to a NGO partner interested in establishing a clinic, to take a strong stand and pressure the law school, one with over 400 years of history, to adopt the clinic model. The deans rejected the concept following a number of discussions with the NGO.
27 This includes refugee law as well as housing, access to justice, womens' rights, etc.

28 Universities in Austria instituted a minimal tuition of $\$ 750$ for the first time in 2000. Other European universities are considering similar measures. 
- $\quad$ Need expressed from certain sectors: Though the average European social system provides good general care and coverage to its citizens, there remains a large need for lawyers with human rights and poverty oriented legal experience. Clinics fit in nicely.

\subsection{Creating the necessary environment}

Resistance to clinical legal education can be broken down through better co-ordination of efforts to promote, develop and sustain different models. This may come in the form of partnerships with existing clinical programs in North America. ${ }^{29}$ But this will only cover a small number of clinical programs and will require a huge investment of time to create awareness on both sides of the Atlantic.

The strategies developed in these partnerships regarding refugee law clinics might be applicable to other clinical programs:

- An external support partner with clear interest in the success of the clinics was identified. In this case it was UNHCR supported by the Legal Aid-Legal Clinics network.

- Responsible professors with time and energy to commit to the establishment and development of the clinics were identified and supported.

- National NGOs with mission statements that included legal aid for asylum seekers ad refugee were approached.

- Strategies were developed between this team as to how to best approach the university and the availability of resources.

- $\quad$ Outreach was done in the form of open house seminars for students.

This process was monitored in a number of universities and lessons were shared for feedback.

\subsection{Existing stumbling blocks}

The argument raised above regarding the need to identify the proper long term support partner for a clinic in the absence of a well endowed university program needs to be discussed further. Currently, there is an absence of credible partners to help support the general establishment and further development of any university based clinical program. ${ }^{30}$

There is clearly a need for labour law clinics throughout Europe as legal services for the average blue collar worker or immigrant are too expensive. Trade unions and/or the International Labour Organization (ILO) would be the logical long term partners for such clinics. Neither have been approached nor are they active.

Amnesty International Human Rights Watch and/or the International Helsinki Federation would be the appropriate partners for human rights oriented clinics. These organisations do not have the capacity or the expertise to do so, at least not at the present stage. ${ }^{31}$

29 In the field of refugee law clinics this comes in the form of the "Sister's Program", linking refugee law clinical programs in North America and Central Europe.

30 Refugee law clinics receive support from UNHCR but this is done on a clinic by clinic basis and is not UNHCR policy.
31 National Helsinki Committees are active in the refugee law clinic field. As with the case of UNHCR, this is not a central policy but a national preference. A complete review of existing refugee law clinic support partners was done by the author in 1999 and updated in 2000. The review analyzed current and future capacity and interest. 
Again, the approach taken by the refugee law clinics regarding support partners might yield some valuable lessons learned. This would require that there be organizations ready to take on the task of promoting and developing clinical legal education programs. A credible organization, at the time of the writing of this paper, does not exist.

\subsection{Two helpful case studies}

The Hungarian Case: The work of the Hungarian Helsinki Committee (HHC) and ELTE University in Budapest is an excellent example of the right clinic formula. HHC provides legal aid for a number of target groups in Hungary including asylum seekers and refugees. Working in partnership with ELTE law school since 1997, the HHC model has been adapted to other cities in Hungary where legal aid is needed.

Lawyers and private law firms are fully integrated into a clinic program that provides refugee law, theory and lawyering skills combined with a year of externship with HHC supported lawyers. Though the project is in its development stage, effort has been made to integrate modern case and office management practices from other programs and the clinic team is engaged in a number of skills development partnerships with North American universities. ${ }^{32}$

This overall development is part of a larger strategy developed between HHC and Legal Aid-Legal Clinics in 1999. This partnership has included a number of seminars for refugee law clinics in the region. HHC will play a large role in the overall development of refugee law clinics in the CEBS through to 2004.

The Austrian Case: The Hungarian Case is somewhat unique as there was strong support from ELTE law school and HHC from the outset. Developments in Austria are following the normal pattern of doubt and resistance.

Two Austrian universities were identified in 2000 as potential clinical education standard bearers; Graz and Salzburg. Both universities have an ancient legal education tradition dating back to the 16th century. Neither experiments with clinical legal education.

In 2000 the author met with two professors from both universities to assess the interest and the potential stumbling blocks towards the development of refugee law clinics. The professors showed a great deal of interest and admitted to experimenting with case studies and simulations in their courses to provide students with some additional skills. Development plans were drawn up with each team that included future meetings with responsible deans and other faculty, as well as student open houses, etc.

In 2001 the author revisited both universities to assess development. The Salzburg team got as far as discussing the concept with local NGOs and was able to organize a partnership meeting for June 2001. The Graz clinic, operating through the new European Training Academy at the university, began to hold weekly courses on refugee law complemented with skills development sessions for students. A practical element was due to follow in autumn 2001.

Though the professors are not trained in clinical legal education, they incorporate a number of non-traditional teaching methods that allow students to move closer to practical knowledge of the law. Neither has reached the stage that involves externships.

32 Management support has come in the form of working seminars for the HHC team with lawyers from the
Catholic Charities Legal Aid Network and the Georgetown University Clinic program. 


\section{Promoting Refugee Law as a Means of Challenging the Status Quo at University Level Education In Europe: The Role of the Refugee Law Clinic}

Careful planning and development was present at both universities and the stumbling blocks mentioned above were largely avoided as a result.

\section{SUMMARY AND PRELIMINARY CONCLUSIONS}

To say that clinical legal education is revolutionizing European legal studies is an exaggeration. The changes and developments should be noted, in particular in the field of refugee law development. There are valuable lessons learned that other clinical programs may want to filter into their own scenarios.

Protection issues are different throughout Europe. The CEBS, as both transit countries and countries of asylum, have more or less newly developed legislative frameworks and practices. It has been recognized that the CEBS currently face certain economic constraints and a shortage of well trained refugee lawyers who are able to function within these systems as providers of legal aid or as decision takers. This may be the reason why clinics have developed more rapidly in the CEBS. In addition, the pending entry into the EU of many of the CEBS adds another level of complexity to their asylum systems. Therefore, clinics in the CEBS are ideally poised to provide the next generation of lawyers with the training they need to operate in a more sophisticated asylum system.

The countries of the CIS are transit countries and/or recipients of mass influxes of asylum seekers. In addition, their asylum systems are in the first stage of development. Legislative framework and practice, if any, are in their infancy. Needs are more short-term and stop-gap regarding strengthening the current protection capacity and more long-term regarding the creation of well trained refugee lawyers. Therefore clinics could be used to train a large number of decision takers to handle the current need with an overall goal of providing the developing asylum systems with the necessary practitioners.

Western European/EU States have more sophisticated asylum systems with long standing traditions of refugee protection and practice. Legal aid is normally provided by State authorities and supplemented by NGO support. According to some, the quality of decision taking and legal aid is sometimes in question in a number of States. In addition, legal aid in Western Europe is expensive. Clinics have the opportunity to complement the current legal aid structures and provide a pool of well trained refugee lawyers and/or decision takers.

As high quality, low cost legal aid for asylum seekers and refugees remains a universal challenge the clinic concept remains one such way to meet the growing protection needs in countries around the globe. Careful research and analysis of the protection needs of each country will be the key to determine whether a refugee law clinic has a place in the national protection scheme.

\subsection{Needs}

There is a clear lack of experienced clinical teachers in Europe. The programs that do exist manage because there is a professor with a great deal of dedication who keeps the program alive. Educational tools and resources are being developed but financial resources are scarce. This inhibits development over the long term and invites burn out on the part of the professors who invest not just their time but their money as well.

General clinical programs desperately need an organization that can support the varied levels of the clinic including skills for professors and lawyers, training tools and resources and exchange possibilities. Support at this stage is piecemeal and without a strategic outlook for the future. 


\subsection{Existing resources}

Interest has been raised in the clinical concept over the past two years and a number of professors have actively sought support and information. This is probably the most telling sign. The human resources are available but they need to be informed and reassured that the time they invest in developing clinical legal programs will receive support from outside. ${ }^{33}$

It is worth mentioning again that there are more than enough clients in Europe who would benefit from the clinical programs.

\subsection{Where to go from here?}

First and foremost, clinicians who want to take an active role towards the development of clinical programs elsewhere need to make themselves known. The resources that are currently available should be compiled and circulated. Professors from outside of North America need to be provided with a clear set of guidelines and contact persons so that the first steps, such as putting together a clinic team and a resource assessment, can move forward in parallel.

Once a strategy has been developed, organizations such as Amnesty International and ILO should be approached for support and guidance. Developing programs will find it easier to convince their universities if they know that they can count on outside support.

Lessons learned from the refugee law clinic development might prove useful in this regard.

33 It is interesting to note that clinical legal education has become a rallying cry of a number of organizations now working in China. 